\title{
Applying of Chitosan- $\mathrm{TiO}_{2}$ Nanocomposites for Photocatalytic Degradation of Anthracene and Pyrene
}

\author{
Danila A. Tatarinov*, Sofia R. Sokolnikova, and Natalia A. Myslitskaya \\ Department of Physics, Kaliningrad State Technical University, 1 Sovetsky prospect, Kaliningrad 236022, Russia
}

*e-mail: dan.tatarinov@mail.ru

\begin{abstract}
In this work, chitosan- $\mathrm{TiO}_{2}$ nanocomposites (NCs $\mathrm{CS}-\mathrm{TiO}_{2}$ ) were developed for the photocatalytic degradation of some representatives of polycyclic aromatic hydrocarbons (PAHs). $\mathrm{TiO}_{2}$ nanoparticles (NPs) were synthesized by laser ablation method and their sizes were determined by dynamic laser light scattering (DLLS). Anthracene and pyrene in micellar solution were used as representatives of PAHs. The effect of $\mathrm{TiO}_{2}$ in the composition of prepared nanocomposites on the photodegradation of PAHs in model environments under UV irradiation was studied. The method of solidphase luminescence (SPL) was used to estimate the decrease in PAHs concentrations. Based on the results of the studies carried out, pseudo-first order photodegradation kinetics were plotted. The efficiency of using the nanocomposites for the photocatalytic degradation of anthracene and pyrene was proved. (C) 2021 Journal of Biomedical Photonics \& Engineering.
\end{abstract}

Keywords: titanium dioxide nanoparticles; $\mathrm{TiO}_{2}$; photocatalyst; polycyclic aromatic hydrocarbons; PAH; pyrene; anthracene; chitosan; UV irradiation.

Paper \#3401 received 15 Jan 2021; revised manuscript received 5 Feb 2021; accepted for publication 16 Feb 2020; published online 21 Mar 2021. doi: 10.18287/JBPE21.07.010301.

\section{Introduction}

PAHs are compounds containing two or more fused benzene rings in the molecule. Compounds of this group are found everywhere in the environment. PAHs are dangerous pollutants and are classified as compounds with significant risk to human health [1]. PAHs are dangerous even in small amounts due to their bioaccumulative properties. It was found that the content of PAH group substances in the environment is exceeded, the risk of developing cancer increases many times [2]. In this regard, it is actually to study the methods of degradation of PAHs, in particular with photocatalytic reactions [3].

In this work, $\mathrm{TiO}_{2}$ was used as a photocatalyst, which has high photoactivity and demonstrates potential advantages in the oxidation of ecotoxicants, including PAHs, $\mathrm{SO}_{2}, \mathrm{NO}_{2}$, etc. [3, 4]. It is known that materials with the addition of $\mathrm{TiO}_{2}$ can significantly improve the state of the environment. For example, in the construction industry, research is being conducted to develop an innovative building material containing the $\mathrm{TiO}_{2}$ photocatalyst. Photocatalysis technologies make possible the production of construction materials with advanced functions such as self-cleaning, air purifying and surface self-sterilization [5]. For example, concrete pavements with $\mathrm{TiO}_{2}$ to decompose airborne pollutants and antibacterial ceramic tiles were developed [6]. Moreover, the application of photocatalytic materials for barrier structures, road surfaces and tunnels can be useful in reducing the level of environmental pollution [7].

$\mathrm{TiO}_{2}$ is also used in the field of water treatment. When $\mathrm{TiO}_{2}$ is used to purify aqueous media, hydroxyl radicals are generated during photocatalysis, which act as an oxidizing agent. In this regard, toxic contaminants contained in the purified water decompose to inorganic components without the formation of secondary waste [8].

This article focuses on the possibility of developing and applying biopolymer nanocomposites using $\mathrm{TiO}_{2}$ for the photocatalytic degradation of PAHs in aqueous media. Pyrene (PYRE) and anthracene (ANTR) were chosen as representative compounds of PAHs. The process of photodegradation was studied under various experimental parameters.

\section{Backgrounds}

In the nature, $\mathrm{TiO}_{2}$ has three different types of crystal structure: anatase, rutile and brookite. It is known that 
$\mathrm{TiO}_{2}$ NPs in the anatase phase with a band gap of $3.2 \mathrm{eV}$ exhibit good photocatalytic activity. In case of absorption of a photon with an energy equal to or exceeding the band gap in $\mathrm{TiO}_{2}$, an electron transition from the valence band to the conduction band can occur. After this, the formation of electron-hole pairs occurs due to the formed free vacancies in the valence band. The created electronhole pair has a sufficient lifetime in the nanosecond range to transfer charge to adsorbed particles on the semiconductor surface [9]. Then, excited electrons in the conduction band and holes in the valence band recombine, followed by dissipation of energy in the form of heat. If suitable absorbers are available for trapping an electron or a hole, redox reactions can occur [10]. The scheme of the described photocatalytic processes is shown in Fig. 1.

Photodegradation of PAHs in aqueous media with the addition of $\mathrm{TiO}_{2}$ has been actively studied recently. The authors of Ref. [11] have noted that $\mathrm{TiO}_{2}$ can effectively photocatalyze the oxidation of PAHs, such as anthracene, fluorene, and naphthalene, when irradiated with artificial light or sunlight. In Ref. [12], the photocatalytic degradation of a mixture of $16 \mathrm{PAHs}$ in aqueous $\mathrm{TiO}_{2}$ suspensions with a large surface area illuminated by UV light was studied. The authors of Ref. [13] have proved that the reaction of photocatalysis for pyrene with the addition of $\mathrm{TiO}_{2}$ occurs with the producing of some intermediate products (4-oxapyrene-5-one, 1,6- or 1,8pyrenediones, 4,5-phenanthrenedialdehyde, cyclopenta[def]phenanthrene). As a result, pyrene can finally be mineralized to $\mathrm{CO}_{2}$, which is not a potential pollutant for the environment.

To increase the efficiency rate of $\mathrm{TiO}_{2}$, the authors of Ref. [14] proposed the photocatalytic degradation of naphthalene in water using $\mathrm{TiO}_{2}$ on Raschig glass rings. In the study [15], the photocatalytic degradation of aqueous solutions of naphthalene and anthracene in a thin layer of $\mathrm{TiO}_{2}$ particles on glass substrates was studied. The authors of Ref. [16] have observed that the use of $\mathrm{TiO}_{2}$ in high concentrations for the photocatalytic degradation of PAHs becomes ineffective and the rate of photodegradation decreases with increasing $\mathrm{TiO}_{2}$ concentration. This decrease could be connected with the fact that the titanium particles caused the diffusion of UV light and that reduces the absorption of light in the reaction media. In this regard, it can be efficient to use low $\mathrm{TiO}_{2}$ concentrations for the photocatalytic degradation of PAHs.

In recent years, research into the practical use of polymers for the treatment of aqueous media has become actual. On their basis, ecological materials with various properties have been created, such as sorbents, films and filters, membranes for nano- and ultrafiltration, and functional composite materials [17]. Some biopolymer materials with nanodispersed $\mathrm{TiO}_{2}$ are used to improve the functional properties of nanocomposites and increase the photocatalytic activity of $\mathrm{TiO}_{2}$. One of the prospective biopolymers for solving such tasks is chitosan (CS) the product of chitin deacetylation [18].
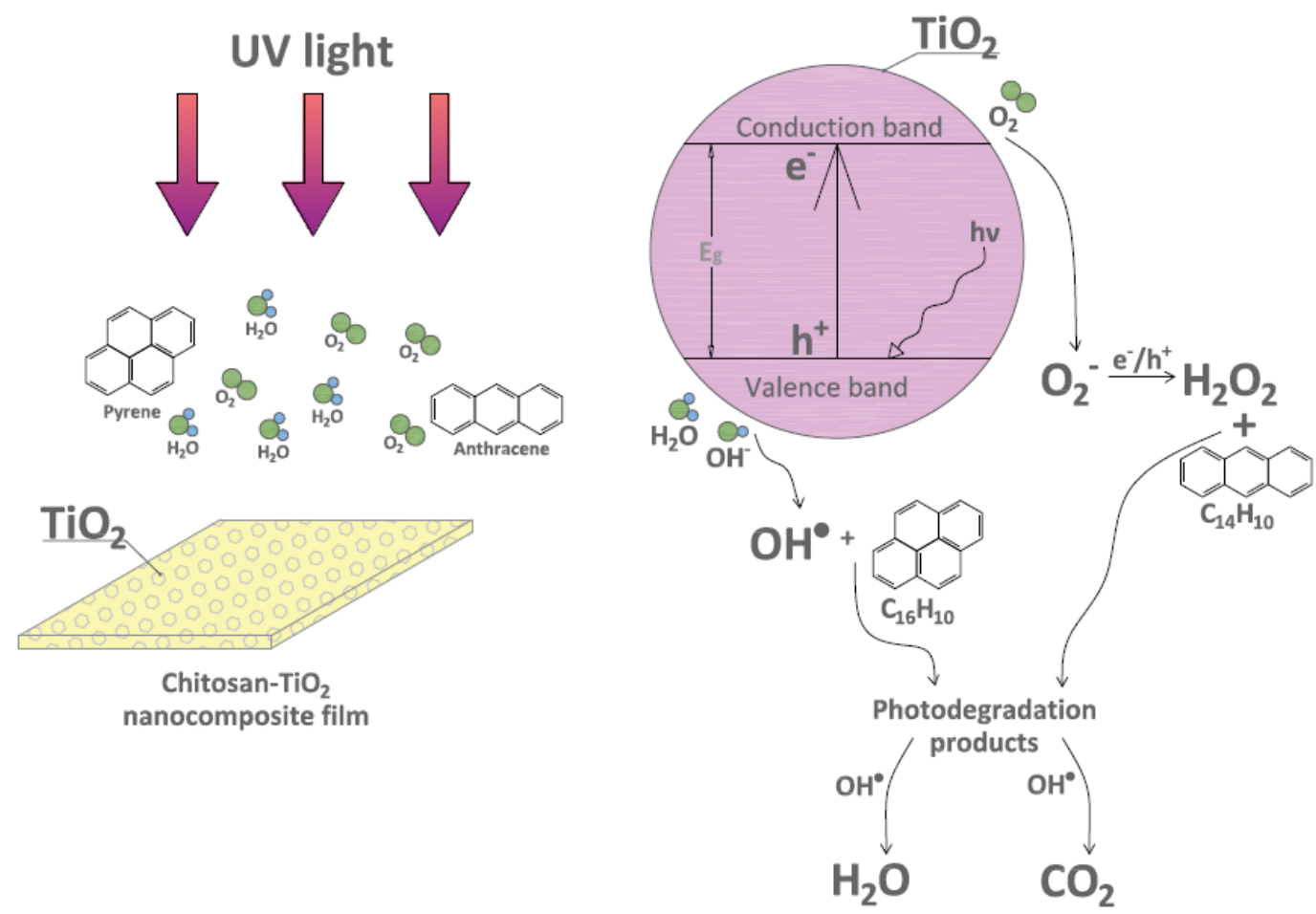

Fig. 1 Scheme of PAHs photodegradation on nanocomposites chitosan- $\mathrm{TiO}_{2}$. 
CS matrices show a high sorption capacity [19-20] and are effective sorbents of such compounds as heavy metal ions, dyes, PAHs, etc. CS has a high ability to chemical modification due to the presence of reactive amino and hydroxyl groups. This allows one to select the different characteristics of polymeric sorbent according to the tasks [21].

\section{Materials and methods}

In this work, the processes of degradation of ecotoxicants of the PAH group were studied in aqueous media. Nanocomposites with the addition of $\mathrm{TiO}_{2}$ based on CS matrices have been developed. In Ref. [22], the authors modified the CS matrices to improve the mechanical and sorption properties. The high sorption capacity of the produced matrices was proved, which is of interest for studying the processes of photocatalytic degradation of some PAHs.

In the study, CS (Diaham LLC, degree of deacetylation $95 \%, \mathrm{M}=1526.45 \mathrm{~g} / \mathrm{mol}$ ) was used as a basis for solid matrices. Also, the composition of the matrices includes polyvinyl alcohol and cetyltrimethylammonium bromide. The matrices were prepared as described in Ref. [22]. However, during the formation of the matrices, $\mathrm{TiO}_{2}$ nanoparticles $\left(\mathrm{TiO}_{2} \mathrm{NPs}\right)$ with mass fraction $\omega_{\mathrm{TiO} 2}=0.15,0.5$, and $1 \mathrm{wt}$. $\%$ of CS were added.

$\mathrm{TiO}_{2}$ NPs were synthesized by laser ablation using a methodology similar to Refs. [23, 24]. A schematic of the installation for producing $\mathrm{TiO}_{2}$ NPs is shown in Fig. 2. For preparing a colloidal solution of $\mathrm{TiO}_{2} \mathrm{NPs}$, a pulsed YAG: $\mathrm{Nd}^{3+}$ laser was used (radiation wavelength $\lambda=532 \mathrm{~nm}$, pulse duration $\tau=11 \mathrm{~ns}$, and pulse repetition rate $v=10 \mathrm{~Hz}$ ). A sample of thin plate Ti $(99.9 \%$ pure) was immersed in distilled water and irradiated with a laser for $\mathrm{t}=60 \mathrm{~min}$. The output laser energy was $170 \mathrm{~mJ}$. During irradiation, the cuvette was constantly moved to avoid crater formation in the titanium plate as a result of ablation.

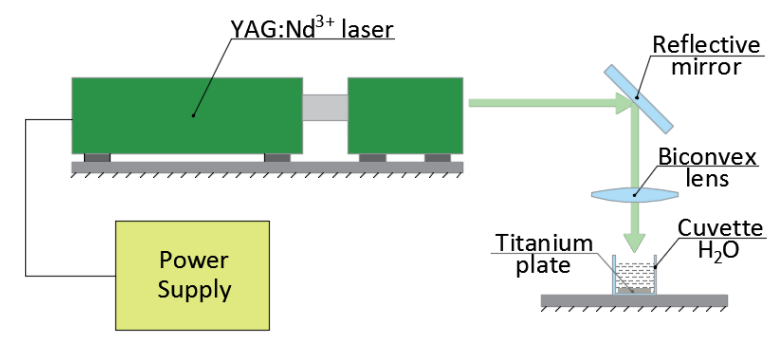

Fig. 2 Schematic of the installation for producing $\mathrm{TiO}_{2}$ nanoparticles.

The obtained $\mathrm{TiO}_{2}$ NPs were studied by dynamic laser light scattering (DLLS) (Fig. 3). The irradiation source was a helium-neon laser $(\mathrm{W}=25 \mathrm{~mW}$; $\lambda=632.8 \mathrm{~nm}$; ray cross-sectional diameter $100 \mu \mathrm{m})$. The prepared samples were placed in a thermostat $\left(\mathrm{t}=25 \pm 0.1^{\circ} \mathrm{C}\right)$. The laser irradiation was scattered by $\mathrm{TiO}_{2}$ NPs participating in the Brownian motion. The scattered light was recorded by a photomultiplier tube with a photon counting system. The correlation function of the scattered light intensity was calculated using a 32bit 282-channel Photocor-FC correlator connected to a computer. The hydrodynamic radius of $\mathrm{TiO}_{2} \mathrm{NPs}$ was calculated from the results of measuring the particle sizes using DLLS and processing the results with the DynaLS program. At the critical level of significance $p=0.05$, the average size of $\mathrm{TiO}_{2} \mathrm{NPs}$ was $\mathrm{R}=270 \pm 46 \mathrm{~nm}$.

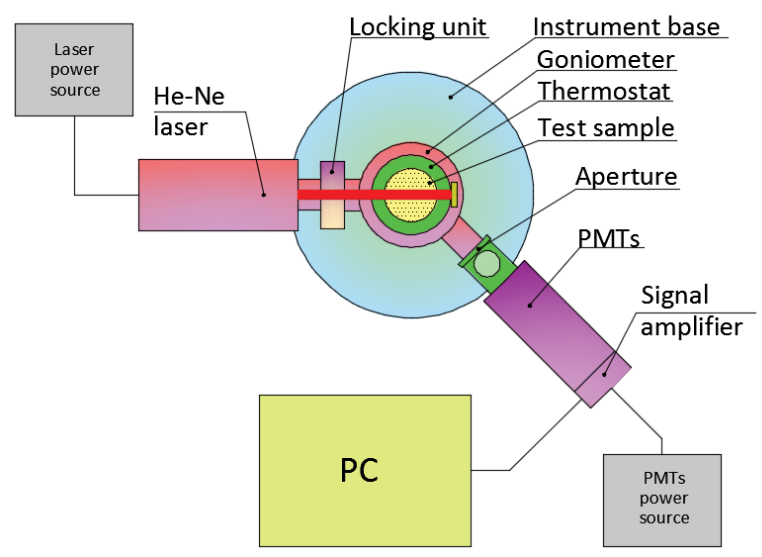

Fig. 3 Schematic of the installation for determining the size of $\mathrm{TiO}_{2}$ nanoparticles by DLLS.

In the study, PYRE and ANTR (Fluka, Germany) were used as model PAHs. PYRE has a characteristic fluorescence spectrum, which is represented by five wellresolved main vibronic bands [25]. ANTR has a fluorescence spectrum similar to pyrene, but represented by four vibronic bands [26]. These representatives of PAHs are not highly toxic, which makes their use in laboratory studies relatively safe [25].

For solubilization of PYRE and ANTR an aqueous solution (distilled $\mathrm{H}_{2} \mathrm{O}, \mathrm{pH}=7$ ) of sodium dioctyl sulfosuccinate was used at a concentration of $10^{-2} \mathrm{M}$. The concentration of selected PAHs representatives in the prepared solutions was $10^{-6} \mathrm{M}$. The $\mathrm{pH}$ values were controlled on a $\mathrm{pH}$ meter (F20-Standard, Mettler Toledo, USA).

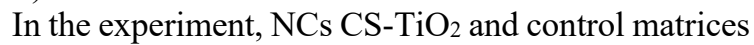
from CS without $\mathrm{TiO}_{2}$ NPs were manufactured. Samples with a size of $2 \times 2 \mathrm{~cm}$ were prepared from the films. Shimadzu UV-3600 Plus spectrophotometer and Shimadzu UV probe data processing program were used for the recording and calculation of UV-visible absorption spectra of $\mathrm{NCs} \mathrm{CS}-\mathrm{TiO}_{2}$ and control samples.

After that, static sorption of the samples was done in PAH solutions for 60 minutes under UV irradiation (UV lamp, power $\mathrm{P}=26 \mathrm{~W}$, wavelength range $\lambda=365-395 \mathrm{~nm})$.

The solid-phase luminescence (SPL) method was used to evaluate the kinetics of PYRE and ANTR degradation on $\mathrm{NCs} \mathrm{CS}_{-} \mathrm{TiO}_{2}$. In this case, PAHs are determined on a solid matrix in the sorbent phase, providing sufficient detection sensitivity [22]. 
HORIBA Fluorolog-3 TCSPC modular system was used for luminescence analysis. Error of measured parameters consists of luminescence intensity measurement and emission monochromator errors. The error of monochromator emission $\pm 0.5 \mathrm{~nm}$ was stated by the HORIBA manufacturer [27].

Statistical processing of the experimental results was made according to the IUPAC method [28]. For a sample with size of $n=7$, the standard deviation was calculated. Then the confidence interval was determined at the mean with a critical level of significance $p=0.05$ and the standard error. Thus, for the values of photodegradation efficiency, the absolute error was 0.02-0.04.

\section{Results and discussion}

The results of UV-visible spectrophotometry of the $\mathrm{CS}_{-} \mathrm{TiO}_{2}$ samples are shown in Fig. 4. The obtained samples were studied: colloidal solution of $\mathrm{TiO}_{2} \mathrm{NPs}$, control samples of solid matrices of CS and NCs CS$\mathrm{TiO}_{2}$.

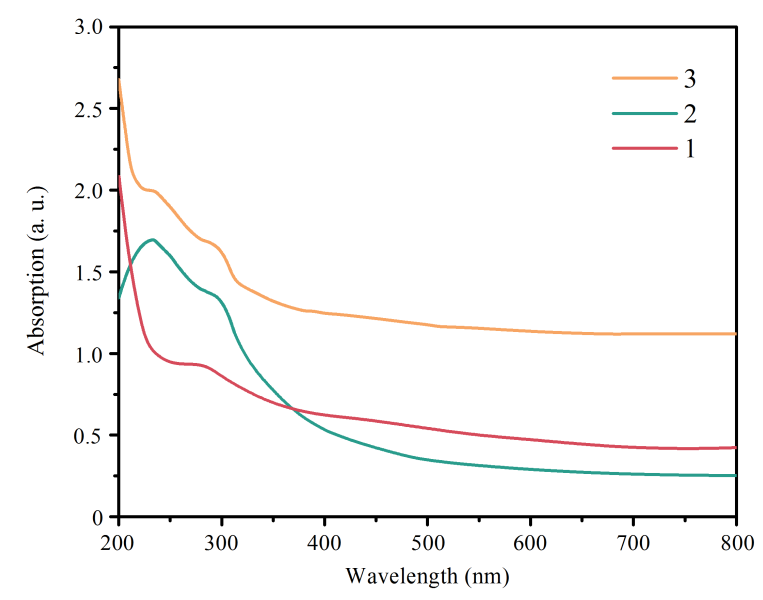

Fig. 4 Absorption spectra: 1 - solid chitosan matrix; $2-\mathrm{TiO}_{2}$ nanoparticles; 3 - nanocomposites chitosan- $\mathrm{TiO}_{2}$.

The absorption spectrum $\mathrm{TiO}_{2}$ NPs (Fig. 4, Curve 2) consists of two bands: one about $230 \mathrm{~nm}$, the second about $300 \mathrm{~nm}$. According to the literature data [29], the absorption bands at these wavelengths are characteristic of the anatase phase of $\mathrm{TiO}_{2}$. The presented spectrum confirms the presence of the anatase phase and indicates a high degree of photocatalytic activity of prepared $\mathrm{TiO}_{2}$ NPs.

In Fig. 4, Curve 1 shows the absorption spectrum of the control matrix of CS. It is known that in the wavelength range of 250-300 $\mathrm{nm}$, absorption maxima are characteristic of chitosan molecules. This is explained by the presence of a chromophore carbonyl group $\mathrm{C}=\mathrm{O}$ formed during the deacetylation of chitin [30]. In Fig. 4, Curve 3 shows the absorption spectrum of the NCs $\mathrm{CS}-\mathrm{TiO}_{2}$. In this case, the absorption band at a wavelength of $230 \mathrm{~nm}$ appears, which is characteristic of $\mathrm{TiO}_{2}$ NPs. This confirms the presence of $\mathrm{TiO}_{2} \mathrm{NPs}$ in the prepared nanocomposites.
A luminescent analysis of the manufactured samples was performed to study the processes of photocatalytic degradation of ANTR and PYRE using NCs CS-TiO 2 . The fluorescence spectra of ANTR $\left(\lambda_{\text {ex }}=340 \mathrm{~nm}\right)$ and PYRE $\left(\lambda_{\mathrm{ex}}=320 \mathrm{~nm}\right)$ on $\mathrm{NCs} \mathrm{CS}-\mathrm{TiO}_{2}$ and control samples of $\mathrm{CS}$ after $\mathrm{UV}$ irradiation $(\mathrm{t}=60 \mathrm{~min})$ are shown in Figs. 5 and 6.

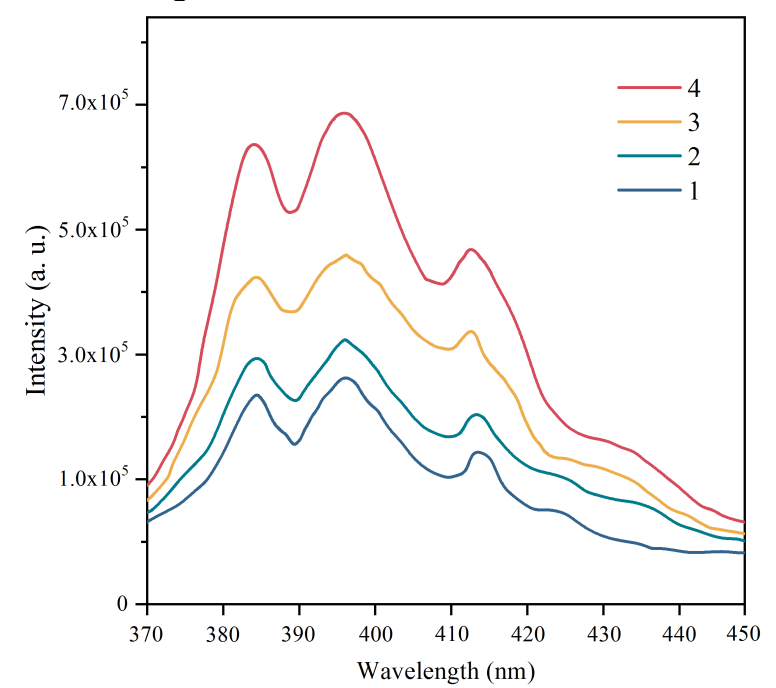

Fig. 5 The fluorescence spectra of anthracene on nanocomposites chitosan- $\mathrm{TiO}_{2}: 1-\omega_{\mathrm{TiO} 2}=1$ wt. $\%$; $2-\omega_{\mathrm{TiO} 2}=0.5$ wt. $\%$; $3-\omega_{\mathrm{TiO} 2}=0.15$ wt. $\%$; 4 - anthracene on control chitosan matrix.

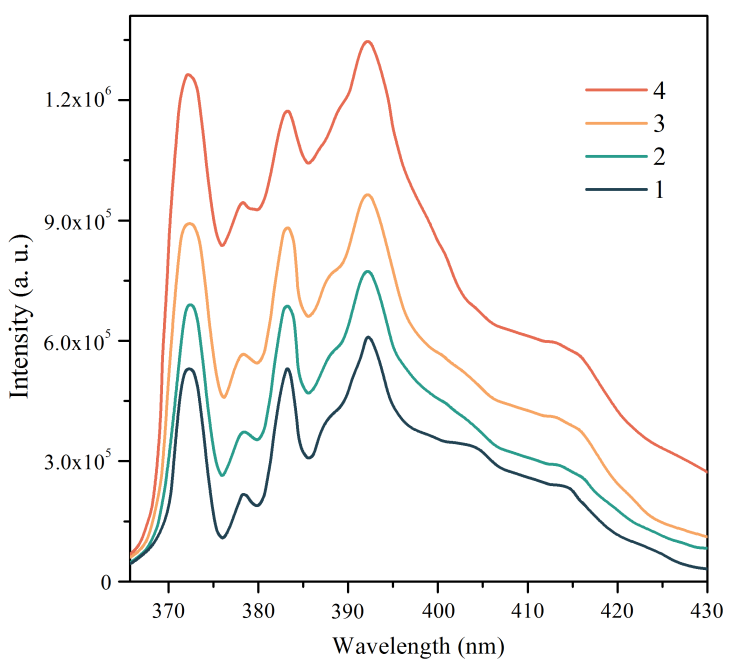

Fig. 6 The fluorescence spectra of pyrene on nanocomposites chitosan- $\mathrm{TiO}_{2}: 1-\omega \mathrm{TiO} 2=1 \mathrm{wt} . \%$; $2-\omega_{\mathrm{TiO} 2}=0.5$ wt. $\% ; 3-\omega_{\mathrm{TiO} 2}=0.15$ wt. $\% ; 4-$ pyrene on control chitosan matrix.

According to the results of luminescence analysis, it can be concluded that the intensity of fluorescence after

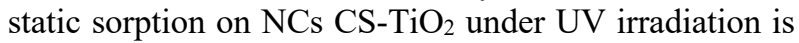
less than the intensity of PAHs after static sorption on control matrices under UV irradiation. The obtained results can be explained by the fact that the $\mathrm{TiO}_{2} \mathrm{NPs}$ in the composition of the manufactured nanocomposites 
photocatalyze the oxidation of PAHs. The graphs also show that the efficiency of using $\mathrm{NCs} \mathrm{CS}_{-} \mathrm{TiO}_{2}$ for photodegradation of ANTR and PYRE depends on the amount of $\mathrm{TiO}_{2}$. The highest degree of PAHs photodegradation is observed in samples with $\mathrm{TiO}_{2}$ content $\omega_{\mathrm{TiO} 2}=1$ wt. $\%$ at $\mathrm{t}=60 \mathrm{~min}$ under UV irradiation.

PAH concentrations for the study of the degradation of ANTR and PYRE during photocatalytic reactions on $\mathrm{NCs} \quad \mathrm{CS}-\mathrm{TiO}_{2}\left(\omega_{\mathrm{TiO} 2}=1 \%\right.$ wt. $)$ were determined by luminescence analysis. For example, in the study [31], the PYRE concentration on solid matrices was determined using a calibration graph. The authors found that the dependence of the SPL intensity on the PAHs concentration on the solid matrix is linear up to $\mathrm{C}_{\mathrm{PAHs}}=2 \times 10^{-8} \mathrm{~g} / \mathrm{l}$. Similarly, the study [32] describes a technique for evaluating the concentration ' of ANTR using luminescence analysis. In this paper, the concentrations of ANTR and PYRE were determined using similar methods to study the photodegradation

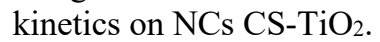

The photodegradation graphs of ANTR and PYRE are shown in Fig. 7. This shows the ratio of $C_{t} / C_{0}$ concentrations on the time $t$. In this case, $C_{t}$ is the concentration of PAHs due to UV irradiation $t$. Similarly, $C_{0}$ is the initial concentration of PAHs before UV irradiation $\left(t_{0}=0 \mathrm{~min}\right)$. Graphs are presented for NCs $\mathrm{CS}_{-} \mathrm{TiO}_{2}$ (Fig. 7, Curves 2, 4) and respective solutions after static sorption onto $\mathrm{NCs} \mathrm{CS}_{-} \mathrm{TiO}_{2}$ (Fig. 7, Curves 1, 3). The graphs show that the efficiency of photodegradation of ANTR and PYRE on NCs CS-TiO reaches 70 and $56 \%$, respectively, after $\mathrm{t}=60 \mathrm{~min}$ under UV irradiation.

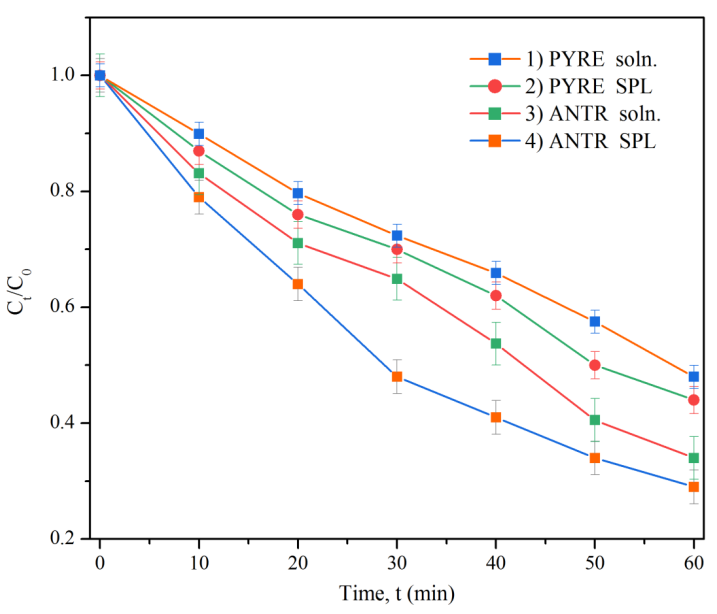

Fig. 7 Photodegradation graphs: 1 - pyrene solution; 2 - pyrene on nanocomposites chitosan-TiO2; 3 - anthracene solution; 4 - anthracene on nanocomposites chitosan- $\mathrm{TiO}_{2}$.

Based on the literature data [33-34], the pseudo-firstorder kinetics for the photocatalytic degradation of PAHs is described by Eq. (1):

$$
-\frac{d \mathrm{C}}{d t}=k C
$$

Then the degradation rate constant $k$ and the half-life $t_{1 / 2}$ during PAH degradation were calculated using the following equations:

$$
\begin{aligned}
& \ln \frac{C_{t}}{C_{0}}=-k t ; \\
& t_{1 / 2}=\frac{\ln (2)}{k} .
\end{aligned}
$$

According to Eq. (2), pseudo-first-order kinetics graphs were plotted for the degradation of ANTR and PYRE under UV irradiation (Fig. 8). This shows the dependence of $\ln \left(C_{t} / C_{0}\right)$ on the time of UV irradiation $t$. The kinetic parameters of the photocatalytic degradation of ANTR and PYRE were calculated. The calculation results are presented in Table 1.

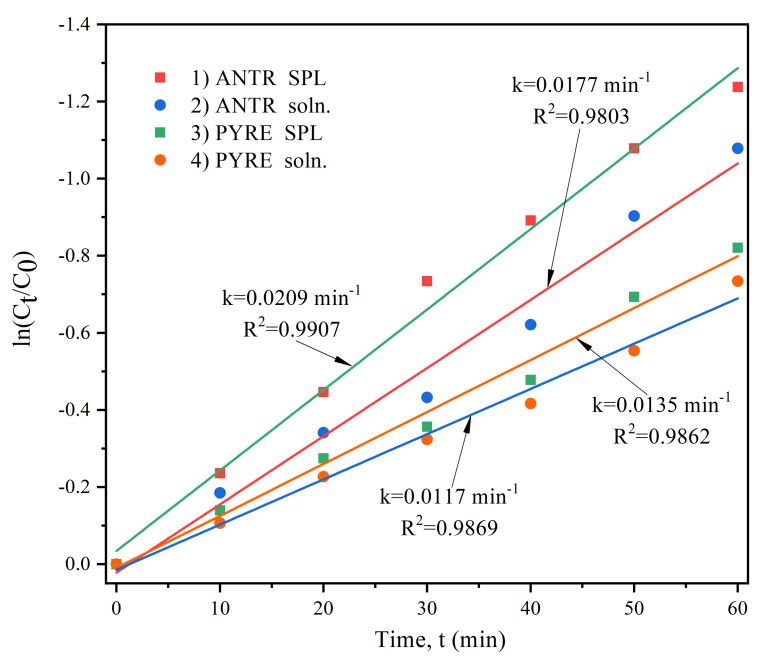

Fig. 8 Graphs of pseudo-first-order kinetics for PAHs degradation under UV irradiation: 1 - anthracene on nanocomposites chitosan- $\mathrm{TiO}_{2} ; 2$ - anthracene solution; 3 - pyrene on nanocomposites chitosan- $\mathrm{TiO}_{2} ; 4$ - pyrene solution.

Table 1 Kinetic parameters of photocatalytic degradation of ANTR and PYRE under UV irradiation.

\begin{tabular}{ccccc} 
PAHs & $\begin{array}{c}\text { Sample } \\
\text { type }\end{array}$ & $\begin{array}{c}\mathrm{k} \\
\left(\mathrm{min}^{-1}\right)\end{array}$ & $\begin{array}{c}\mathrm{t}_{1 / 2} \\
(\mathrm{~min})\end{array}$ & $\mathrm{R}^{2}$ \\
\hline & $\begin{array}{c}\text { Nanocom } \\
\text { posite }\end{array}$ & 0.0209 & 33.165 & 0.9907 \\
\cline { 2 - 5 } PYRE & Solution & 0.0177 & 39.161 & 0.9803 \\
& & & & \\
\hline \multirow{3}{*}{ ANTR } & $\begin{array}{c}\text { Nanocom } \\
\text { posite }\end{array}$ & 0.0135 & 51.344 & 0.9862 \\
\cline { 2 - 5 } & Solution & 0.0117 & 59.243 & 0.9869
\end{tabular}

The experimentally obtained values of the coefficient of determination $\mathrm{R}^{2}$ for photodegradation of ANTR and 
PYRE on $\mathrm{NCs}$ CS-TiO 2 are 0.9907 and 0.9862 respectively. This proved that the photocatalytic degradation of ANTR and PYRE with a sufficient degree of accuracy $\left(\mathrm{R}^{2}>0.95\right)$ corresponded to pseudo-firstorder kinetics.

In general, the results of kinetic studies confirm that NCs CS-TiO 2 are effective for degradation of ANTR and PYRE. For example, in Ref. [34], the photodegradation efficiency of PYRE $\left(C_{\text {PYRE }}=0.5 \times 10^{-6} \mathrm{M}\right)$ in a solution of $\mathrm{TiO}_{2} \mathrm{NPs}$ made according to the method [35] is $35 \%$ after $60 \mathrm{~min}$ under UV irradiation. Also, the authors of Ref. [36] obtained a value of the photodegradation efficiency of PYRE $\left(C_{\text {PYRE }}=0.5 \times 10^{-6} \mathrm{M}\right)$ of $46 \%$ in a solution of pure $\mathrm{TiO}_{2}$ NPs with similar experimental conditions (power of UV lamp $\mathrm{P}=150 \mathrm{~W}$ ). Photodegradation of ANTR was investigated [37] under different conditions of the experiment with an initial concentration $\mathrm{C}_{\mathrm{ANTR}}=1 \times 10^{-6} \mathrm{M}$. The authors obtained the values of the photodegradation efficiency ANTR $60 \%$ after 60 min under UV irradiation.

As a result, in this work, it was possible to achieve better photodegradation of ANTR and PYRE due to

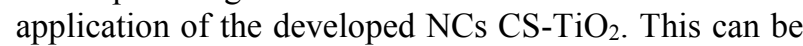
explained by the fact that modified $\mathrm{CS}$ solid matrices were used as the basis for them [22]. Previously, the authors proved their high sorption capacity, which is confirmed by the obtained value of the polarity index of the microenvironment of PYRE molecules. The polarity index is expressed as the ratio of the intensities of the first and third maxima of the fluorescence spectrum $I_{1} / I_{3}=1.08$. Also, a study [38] confirm the high adsorption capacity of $\mathrm{TiO}_{2}$, in this case the PYRE polarity index was $I_{1} / I_{3}=0.98$. This is explained by the fact that PAHs molecules are actively adsorbed on the hydrophobic surface of $\mathrm{TiO}_{2}$ during the whole photocatalytic reaction process due to their low solubility in water.

\section{Conclusion}

A series of experiments demonstrates the efficiency of the degradation of ANTR and PYRE in aqueous media. This is connected to the photocatalytic properties of $\mathrm{TiO}_{2}$ under UV irradiation in the composition of modified CS matrices. In $60 \mathrm{~min}, 70 \%$ of ANTR and $56 \%$ of PYRE were photodegraded under UV irradiation on NCs CS$\mathrm{TiO}_{2}$. Such an effect is achieved due to the high adsorption capacity of the developed NCs CS-TiO 2 .

Also, based on the results of the experiment, graphs of the pseudo-first order photodegradation kinetics were

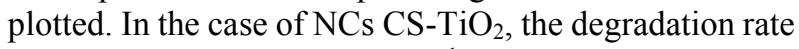
constants $k=0.0209 \mathrm{~min}^{-1}$ for ANTR and $k=0.0135 \mathrm{~min}^{-1}$ for PYRE were calculated. The half-life values were $t_{1 / 2}=33.165 \mathrm{~min}$ for ANTR and $t_{1 / 2}=51.344$ min for PYRE.

The developed NCs $\mathrm{CS}-\mathrm{TiO}_{2}$ are prospective photocatalytic materials for the degradation of PAHs in aqueous media. They can be used for photodegradation of other dangerous PAHs, for example, benz(a)anthracene, benzo(k)fluoranthene, benz(a)pyrene, dibenzanthracene, etc. The method of manufacturing the developed nanocomposites does not require expensive equipment, and they are also convenient to use for photocatalytic reactions. After use, thin-film nanocomposites can be easily recycled without severe environmental pollution.

\section{Disclosures}

All authors declare that there is no conflict of interests in this paper.

\section{References}

1. D. F. Kalf, T. Crommentuijn, and E. J. Plassche, "Environmental quality objectives for 10 polycyclic aromatic hydrocarbons (PAHs)," Ecotoxicology and Environmental Safety 36(1), 89-97 (1997).

2. K. H. Kim, S. A. Jahan, E. Kabir, and R. J. Brown, "A review of airborne polycyclic aromatic hydrocarbons (PAHs) and their human health effects," Environment International 60, 71-80 (2013).

3. L. Zhang, P. Li, Z. Gong, and X. Li, "Photocatalytic degradation of polycyclic aromatic hydrocarbons on soil surfaces using TiO2 under UV light," Journal of Hazardous Materials 158(2-3), 478-484 (2008).

4. S. N. Habisreutinger, L. Schmidt-Mende, and J. K. Stolarczyk, "Photocatalytic reduction of CO2 on TiO2 and other semiconductors," Angewandte Chemie International Edition 52(29), 7372-7408 (2013).

5. W. Zhu, P. J. M. Bartos, and A. Porro, “Application of nanotechnology in construction,” Materials and Structures 37(9), 649-658 (2004).

6. T. Watanabe, "Fabrication of TiO2 photocatalytic tile and practical applications," Fourth Euro Ceramics 11, 175180 (1995).

7. A. H. Hamdany, "Photocatalytic cementitious material for self-cleaning and anti-microbial application," Doctoral thesis, Nanyang Technological University, Singapore (2019).

8. V. Ya. Kofman, "New oxidative technologies of water and wastewater treatment (part 1)," Water Supply and Sanitary Engineering 10, 68-78 (2013).

9. A. L. Linsebigler, G. Lu, and J. T. Yates, "Photocatalysis on TiO2 Surfaces: Principles, Mechanisms, and Selected Results," Chemical Reviews 95(3), 735-758 (1995).

10. M. R. Hoffmann, S. T. Martin, W. Choi, and D. W. Bahnemann, "Environmental Applications of Semiconductor Photocatalysis," Chemical Reviews 95(1), 69-96 (1995). 
11. S. Dass, M. Muneer, and K. Gopidas, "Photocatalytic degradation of wastewater pollutants. Titanium-dioxidemediated oxidation of polynuclear aromatic hydrocarbons," Journal of Photochemistry and Photobiology A: Chemistry 77(1), 83-88 (1994).

12. J. C. Ireland, B. Dávila, H. Moreno, S. K. Fink, and S. Tassos, "Heterogeneous photocatalytic degradation of polyaromatic hydrocarbons over titanium dioxide," Chemosphere 30(5), 965-984 (1995).

13. S. Wen, J. Zhao, G. Sheng, and J. Fu, "Photocatalytic reactions of pyrene at TiO2/water interfaces," Chemosphere 50(1), 111-119 (2003).

14. M. J. Garcia-Martinez, L. Canoira, G. Blázquez, I. Da Riva, R. Alcántara, and J. F. Llamas, "Continuous photodegradation of naphthalene in water catalyzed by $\mathrm{TiO} 2$ supported on glass Raschig rings," Chemical Engineering Journal 110(1-3), 123-128 (2005).

15. B. Pal, M. Sharon, "Photodegradation of polyaromatic hydrocarbons over thin film of TiO2 nanoparticles; a study of intermediate photoproducts," Journal of Molecular Catalysis A: Chemical 160(2), 453-460 (2000).

16. N. K. Salihoglu, G. Karaca, G. Salihoglu, and Y. Tasdemir, "Removal of polycyclic aromatic hydrocarbons from municipal sludge using UV light," Desalination and Water Treatment 44(1-3), 324-333 (2012).

17. A. V. Tkachenko, O. A. Djachuk, "The luminescence of polycyclic aromatic hydrocarbons on modified by surfaceactive agent cellulose," Proceedings of SPIE 6791, 67910P (2008).

18. U. Siripatrawan, P. Kaewklin, "Fabrication and characterization of chitosan-titanium dioxide nanocomposite film as ethylene scavenging and antimicrobial active food packaging," Food Hydrocolloids 84, 125-134 (2018).

19. M. Rinaudo, "Chitin and chitosan: properties and applications," Progress in Polymer Science 31(7), 603-632 (2006).

20. M. Jabli, M. H. V. Baouab, M. S. Roudesli, and A. Bartegi, "Adsorption of acid dyes from aqueous solution on a chitosan-cotton composite material prepared by a new pad-dry process," Journal of Engineered Fibers and Fabrics $6(3), 1-12(2011)$.

21. C. Gerente, V. K. C. Lee, P. L. Cloirec, and G. McKay, "Application of chitosan for the removal of metals from wastewaters by adsorption-mechanisms and models," Critical Reviews in Environmental Science and Technology 37, 41-127 (2007).

22. D. Tatarinov, S. Sokolnikova, and N. Myslitskaya, "Solid-phase luminescence of pyrene in chitosan adsorbents," Journal of Biomedical Photonics \& Engineering 6(1), 010305 (2020).

23. S. C. Singh, R. K. Swarnkar, and R. Gopal, "Synthesis of Titanium Dioxide Nanomaterial by Pulsed Laser Ablation in Water," Journal of Nanoscience and Nanotechnology 9(9), 5367-5371 (2009).

24. A. M. Ivanov, N. A. Myslickaya, and M. S. Kapelevich, "Nanoparticles producing by means of laser ablation and optic methods of their features study," KSTU News 23, 18-24 (2011) [in Russian].

25. K. H. Kim, S. A. Jahan, E. Kabir, and R. J. Brown, “A review of airborne polycyclic aromatic hydrocarbons (PAHs) and their human health effects," Environment International 60, 71-80 (2013).

26. K. Datta, A. K. Mukherjee, "Study of quenching of anthracene fluorescence by [60]fullerene," Spectrochimica Acta Part A: Molecular and Biomolecular Spectroscopy 65(2), 261-264 (2006).

27. Fluorolog-3 Operation Manual rev. G, HORIBA Instruments Incorporated, USA (2014).

28. L. A. Currie, G. Svehla, "Nomenclature for the presentation of results of chemical analysis," Pure and applied chemistry 66(3), 595-608 (1994).

29. K. Karthikeyan, A. Nithya, and K. Jothivenkatachalam, "Photocatalytic and antimicrobial activities of chitosan-TiO2 nanocomposite," International Journal of Biological Macromolecules 104, 1762-1773 (2017).

30. K. V. Reut, N. V. Dolgopyatova, V. Yu. Novikov, N. M. Putintsev, I. N. Konovalova, and Yu. A. Kuchina, "Optical activity and spectrophotometric characteristics of chitosan solutions obtained from the Kamchatka crab and the Arctic shrimp," Vestnik of MSTU 16 (3), 580-585 (2013) [in Russian].

31. S. M. Rogacheva, E. V. Volkova, M. I. Otradnova, T. I. Gubina, and A. B. Shipovskaya, "Solvent Effect on the SolidSurface Fluorescence of Pyrene on Cellulose Diacetate Matrices," International Journal of Optics 2018, 1-6 (2018).

32. G. L. Green, T. C. O'haver, "Derivative luminescence spectrometry," Analytical Chemistry 46(14), 2191-2196 (1974).

33. Z. H. Luo, C. L. Wei, N. N. He, Z. G. Sun, H. X. Li, and D. Chen, "Correlation between the Photocatalytic Degradability of PAHs over Pt/TiO2-SiO2 in Water and Their Quantitative Molecular Structure," Journal of Nanomaterials 2015, 1-11 (2015).

34. H. Soni, N. Kumar, K. Patel, and R. N. Kumar, "Investigation on the Heterogeneous Photocatalytic Remediation of Pyrene and Phenanthrene in Solutions Using Nanometer TiO2 under UV Irradiation," Polycyclic Aromatic Compounds 40(2), 257-267 (2017).

35. H. Soni, J. N. Kumar, K. Patel, and R. N. Kumar, "Photocatalytic Decoloration of Three Commercial Dyes in Aqueous Phaseand Industrial Effluents Using TiO2 Nanoparticles," Desalination and Water Treatment 57, 63556364 (2016).

36. M. K. Saloot, S. M. Borghei, and R. H. S. M. Shirazi, "Evaluation of the photo-catalytic degradation of pyrene using Fe-doped TiO2 in presence of UV," Desalination And Water Treatment 169, 232-240 (2019).

37. F. F. Karam, F. H. Hussein, S. J. Baqir, A. F. Halbus, R. Dillert, and D. Bahnemann, "Photocatalytic Degradation of Anthracene in Closed System Reactor," International Journal of Photoenergy 2014, 1-6 (2014). 
38. X. Jin, Y. Kusumoto, "Spectroscopic studies of pyrene adsorbed to titanium dioxide," Chemical Physics Letters 378(1-2), 192-194 (2003). 